\title{
Artistic Exploration into Muslim's Funeral
}

\section{Zhang Ying}

School of Humanities of Xi'an University, Xi'an, Shaanxi, 710065

\author{
Keywords: Huo Da, Muslim's Funeral, Plot, Structure, Beijing flavor
}

\begin{abstract}
Muslim's Funeral, Huo Da presents "the vicissitude of a Muslim family in the 60 years from 1919 to 1979, including the destiny changing of three generations and the twisting love tragedy of two ages.” In the novel, Huo Da created a series of vivid figures such as Han Ziqi, Liang Junbi, Liang Bingyu, Han Xinyue and Chu Yanchao in a well-structured manner, with undulating plots and strong Beijing flavor. It is "a unique masterpiece in the flourishing modern literary world of China”.
\end{abstract}

\section{Introduction}

Published in 1988, Muslim's Funeral is the novel masterpiece of the woman writer Huo Da. With a length of 50 thousand words, the work tells "the vicissitude of a Muslim family in the 60 years from 1919 to 1979, including the destiny changing of three generations and the twisting love tragedy of two ages.” It presents the collision and fusion of Islamic culture and Chinese culture, which are painful and inevitable. It is just the way how the Chinese history continues and develops, namely, independent of man's will.” Bing Xin (original name Xie Wanying) appraised this novel as a unique masterpiece in the flourishing modern literary world of China, quite independent. It induces 'a resounding effect' with unique plot and style”.

It tells a story happened in Beiping at the beginning of the Republic of China. Liang Yiqing, the owner of Qizhenzhai, was a master of jade polishing. Because of the admiration to Zheng He, he received the order of $\mathrm{Pu}$ Shouchang, the owner of Hui Yuanzhai - making a jadeware named Nautical Chart of Zhenghe for Shamoon - Hunter, an Englishman. Upon the coming of the three-year deadline when the work was to be finished, Liang Yiqing broke the right arm of Zhenghe on the jadeware by mistake due to overwork and fatigue. Seeing all his efforts wasted, he then died of hematemesis upon such a psychological attack. At this time, Pu Shouchang went on the scamp and blackmailed Liang Yiqing's family. For revenge, Han Ziqi, the apprentice of Liang Yiqing, resolutely acknowledged Pu Shouchang as his master and served as an apprentice of Huiyuanzhai to continue the carving of Nautical Chart of Zhenghe. After completion of the jadeware, Han Ziqi carved "Made by Liang Yiqing and Han Ziqi" at the bottom of the jadeware, and then got acquainted with the English jade merchant Shamoon - Hunter. Two years later, Han Ziqi left Huiyuanzhai and returned back to Qizhenzhai under the encouragement of Shamoon·Hunter. Liang Junbi, the eldest daughter of Liang Yiqing married Han Ziqi out of gratefulness. Under the help of Shamoon·Hunter, Han Ziqi revitalized Qizhenzhai and made it famous all over the jade industry in Beijing after ten years. Han Ziqi bought Boyazhai from a police detective chief, which originally belonged to an old man fascinated in jadeware. After acquisition, he also looked for and collected beautiful jades all over the world like the old man, and then studied and appreciated them. In order to protect the jades collected, Han Ziqi took Liang Bingyu, his sister-in-law who was still studying in Yenching University to England for refuge along with Shamoon·Hunter just before the outbreak of Anti-Japanese War. And his wife Liang Junbi did not go together for her deep feeling on the family property. In the foreign country, Han Ziqi and Liang Bingyu fell in love and got married 
privately, and then had a daughter named Han Xinyue. After the Anti-Japanese War, they got back to Bo Yazhai in Beijing with their daughter. Because of the unbearable humiliation from her sister Liang Junbi, Liang Bingyu required Han Ziqi to get back to London with her, but he was reluctant to leave his property and family in China. In despair, Liang Bingyu went to England just with a letter and a photo to her daughter. At the beginning of 1960s, Han Xinyue grew up and was admitted to Beijing University. There, she fell in love with her class teacher Chu Yanchao. Upon an accidental faint, Han Xinyue was diagnosed as a fatal disease - rheumatic valvular heart disease. It was Chu Yanchao's love that gave much confidence to Han Xinyue to beat the disease. However, Liang Junbi opposed to their love just for the reason that Chu Yanchao was not a Muslim. After knowing that Liang Junbi was not her biological mother, Han Xinyue was knocked down by such a great spiritual attack and got ill again and was sent to the emergency room. Finally, Han Xinyue died with the regret of not having the last chance to see her lover Chu Yanchao. Later, the Cultural Revolution broke out, Han Ziqi's family was checked by the Red Guards, and the precious jades collected by Han Ziqi was also confiscated. Then Han Ziqi got sick. In pain and confession, he remembered his master Liang Yiqing, the wandering Liang Bingyu and his dead daughter Han Xinyue. On his deathbed, he told a shocking secret to his family: he was the Han people rather than Muslim. In the summer of 1979, Liang Bingyu returned to Boyazhai in Beijng after 33 years of wandering, but she could never see her husband and daughter she yearned to see day and night. On June 5 of the lunar calendar, the birthday of Han Xinyue, Liang Bingyu saw a middle-aged man (Chu Yanchao) just standing near a tree in sorrow and sad in front of Xinyue’s tomb.

\section{The Artistic Characteristic of Muslim's Funeral}

The most remarkable artistic characteristic of Muslim's Funeral is that the author shaped a series of vivid figures like Han Ziqi, Liang Junbi, Liang Bingyu, Han Xinyue and Chu Yanchao.

Han Ziqi is the hero of the novel, a jade craftsman. Throughout his glorious and sad life with twists and turns, he created the glory in his career by virtue of agile mind, open thought, self-respect and self-strengthening and resilient character. However, his life was also full of sorrow due to tragedy of love, loss of jades and disillusionment of dream. Han Ziqi got great changes in character in his first half and second half of life. In his first half, Han Ziqi was courage and upright: when he broke a jade bowl in Qizhenzhai, he had nothing to pay for it and insisted on compensating by serving as a laborer; he grew from an unknown orphan into a "Jade Master” famous all over Beijing just with two hands; facing his master's death and family decline, he endured humiliation and resolutely acknowledged Pu Shouchang as his master to learn skills hard despite of the infamy of betraying master and mistake by his master's wife and daughters. Once he learned the skills well, he resolutely broke up with the enemy Pu Shouchang and returned back to his own master's family and shouldered the burden of revitalizing his master's family and estate; he married Liang Junbi out of personal loyalty; when seeking refuge in England, he broke through the worldly obstacle and get married with his sister-in-law, Liang Bingyu. However, in his second half of life, Han Ziqi lived in quietness and learned to endure but was indecisive and hesitate: despite of no love to his wife Liang Junbi, he did not devoiced with her for afraid of the bad reputation, and always tolerated her unreasonable trouble-making; he helplessly saw his lover Liang Bingyu leaving home with no decision; he could neither afford losing lover nor losing family; he was afraid of both losing his treasurable jades and suffering trouble or disaster..., so he just muddled along in unhappiness. Although Han Ziqi behaved just like two different persons in his first and second half of life, there was a main line throughout his life, that is, fascination to jade. Because of the fascination to jade, he left Tuluoyeding who adopted him and planned to pilgrimage, and then acknowledged Liang Yiqing 
as his master; for revitalizing the jade industry, he married Liang Yiqing's eldest daughter Liang Junbi, inherited the legacy of "Jadeware Liang" and won the reputation of "Jade Master"; for protecting the jade, he did not hesitate to leave his wife and son and went to England; for safeguarding the jade, he betrayed his love to Liang Bingyu and stayed together with his wife Liang Junbi. Finally, he died for jade. It is just the jade that brings the glory of his career and creates his tragic life.

Liang Junbi, one of the heroines, is his master's eldest daughter and also his principal wife. She is a figure with strong tragedy color, lovely, respectable, sad and hateful. She was clever, competent, unyielding, shrewish and cunning: as a 12-13 years old girl, she shouldered the burden of her father's workshop just like a small "counting house” of her father Liang Yiqing; after her father's death, she properly handled his funeral, fed her mother and younger sister by her own and well managed the family; facing forcing and threatening of Liang Shouchang, she showed no fear and no yielding; when Han Ziqi returned back from Huiyuanzhai, she bravely married him against common sense and took care of him with no complaints. However, she was also bullying, narrow-minded and grumpy: although polygamy was allowed in the marriage system in Muslim's Funeral, she still broke up Han Ziqi and Liang Bingyu by the reason of the religious discipline "Allah strictly forbids...marrying two sisters" in the Holy Qur'an, and kept on revenging on their daughter Han Xinyue; she forced the housekeeper to leave without mercy as she suspected that the housekeeper stole the ring; she destroyed the love of her son Han Tianxing and Rong Guifang as well as that of Han Xinyue and Chu Yanchao. Finally, along with the death of Han Xinyue and critical illness of her husband, she awakened to the truth and restored the humanity. She placed all her emotion on her husband - "Mrs. Han cannot contain the deep sorrow and clung the face to her husband's hands, with tears flooding the hands which had been overworking for Qizhenzhai and the family all his life. However, her husband told her a secret on his deathbed: he was not a Muslim. This was doubtlessly a great shock to Liang Junbi who was a pious Muslim and strictly observed the Muslim religious disciplines. She fell into deep sorrow.

Liang Bingyu, the younger sister of Liang Junbi, is Han Ziqi's concubine and his master's younger daughter. She is a clever, diligent, enterprising, impulsive and independent Muslin figure who has affection and faith and dares to love and hate: she received good education from childhood and was then admitted to Yenching University. Under the background that "the turbulent North China can hardly ensure one to study peacefully", she went to England with her brother-in-law without permission. In England, she was admitted to University of Oxford and earned the love of Oliver, the son of Shamoon Hunter. Although she did not love Oliver, she was very painful and almost broke down mentally when hearing of Oliver's death. She bravely fell in love with her brother-in-law and had a daughter Han Xinyue, but after returning China with her husband Han Ziqi and daughter, she went to England again in a rage after quarreling with her elder sister.

Han Xinyue is the daughter of Han Ziqi and Liang Bingyu. She was beautiful, gentle, talented and full of rebellious spirit but died at an early age. It is a figure with sorrow and beauty. Han Xinyue lost her mother's love since childhood and lived cautiously under the hostility of her maternal aunt. Originally she was the fruit of their parents' love, but innocently suffered from the mental torment for the reason of her parents. So she bore the heavy cross both psychologically and physiologically. She studied well and received the tender love of her father and brother. At the age of 17, she was admitted to Department of Western Languages of Beijing University and owned a pure love. In the face of love, she was brave and fearless despite of the pressure from her family, nation and religious disciplines. But finally, Han Xinyue died at an early age and left an indelible memory in the heart of her lover Chu Yanchao. 
Chu Yanchao, the class teacher and lover of Han Xinyue, is persevering, broad-minded and unconventional with lofty ideals. He gave up the ideal of being a translator for his father's reason. He did not join the Party, or have salary raise or get promotion, but he was never discouraged. Instead, he insisted on translating New Stories of Lu Xun (original name Zhou Shuren, a famous writer of China) in spare time. He loved the work and life and treated his students, translation cause and his plants with great care. He was loyal and faithful to his love. After knowing the serious disease of Han Xinyue, he insisted on marrying her despite of his family's objection.

Besides, the novel has distinct features in narrative structure. In the work, the author adopts the writing technique of flashback for many times to make the story more complicated, which can consequently push the plot forward with climaxes and show the tragic destiny of figures. In the flashback structure, the author is skilled at setting suspense. She set puzzles one after another at the beginning and then revealed them one by one, to achieve the artistic effect of thrilling and exciting plot. For example, in the preface of the novel, the readers were first brought into contact with an old woman of complicated feelings in a hurry. What does the old woman want to do? And why does she have such feelings and behaviors? After reading the preface, the readers are unconsciously entrapped by the suspense set by the author and are eager to go on reading. However, these suspenses are revealed at the end of the novel, making the readers understand everything naturally and comprehend the feelings of figures at the beginning. Such a puzzle-solving flashback structure places the readers in a puzzling and puzzle-solving cycle, which enhances the richness and ups \& downs of the story.

\section{Conclusion}

The unique narrative structure and deep sense of culture and history bring the readers to the ordinary resident of Beijing society, making readers taste the life and thought of the Hui people living in Beijing and realize the deep secret of history and culture. Meanwhile, the readers can also appreciate the regional customs of Beijing with unique connotations. The detailed depiction of the local buildings in Beijing, rich combination of the customs and feelings of marketplace in Beijing, as well as authentic and vivid words of characters together create the rich Beijing flavor of the novel, presenting a picture of regional culture and customs.

The only shortcoming of Muslim's Funeral lies in that the novel is over dramatization with occasionality, coincidence and tragedy combined together. It is feigned but lack of naturality, fantastic but lack of authenticity, really incredible for the readers.

Pro: This paper refers to the achievement of Shaanxi Social Sciences Fund Program "Study on Spatial Awareness of Shaanxi Literature in the New Period”, No.: $2016 J 009$.

Introduction to the author: Zhang Ying (1979- ), female, Xi'an of Shaanxi, Master Degree of Chinese Philology, Associate Professor of School of Humanities, Xi'an University, research area: Chinese contemporary literature history.

\section{References}

[1] Li Zichi, Muslim's Funeral and Maodun Prize for Literature. Hainan: Journal of Hainan Normal University, 1998 (4).

[2] Li Chunzi, Simple Analysis on the Narrative Structure of Muslim's Funeral. Anhui: Anhui Literature, 2008 (3).

[3] Qian Zhengang, A Sad Melody of Love - On Reading the Long Novel Muslim's Funeral. Beijing: China Culture Daily, 1991-05-26. 
[4] Huo Da, Muslim's Funeral. Beijing: Beijing Shiyue Literature and Art Press, 2007.

[5] Tong Qingbing, A Course of Literary Theory. Beijing: Higher Education Press, 2004. 